IIUC STUDIES

ISSN 1813-7733

Vol.- 6, June 2010 (p 65-76)

\title{
Vindication of Newman's Views on Liberal Education from Contemporary Perspective
}

\author{
Mohammed Sarwar Alam*
}

\begin{abstract}
Through his provocative and evocative lectures at the Catholic University of Ireland, John Henry Cardinal Newman (1801-1890) appealed to incorporate liberal education in university education to form a better and sounder society. Endorsing Newman's views/thesis, this paper argues that colonially shaped, commercially motivated and morally bankrupt higher education system has strained liberal education to a large extent. And predictably, now we are perhaps experiencing an increasingly paradoxical scenario of an inhuman society by the human beings. In spite of predictable and unpredictable changes in social dynamics and paradigms since Newman expressed his views, this paper seeks to arrive at an understanding that his insightful defence of liberal education is still rewardingly relevant.
\end{abstract}

John Henry Cardinal Newman's lectures on the aims of education were delivered in Dublin at the newly-founded Catholic University of Ireland. These lectures were published in 1852 and titled "The Idea of a University". His lectures are a classic statement of the value of "the disciplined intellect" (975) that can be developed by a liberal education rather than by a technical training. Times have changed and there have been horizontal changes in social dynamics and paradigms across the globe. Nevertheless, Newman's universal appeal in defence of liberal education in higher education is more relevant than ever before. Naturally liberal education has assumed many forms across different times and places, with the ultimate aim to humanize the human society. Echoing Newman's views, this paper argues how colonial shaping, commodification or commercialization and marked absence of moral objectives have strained the spirit of liberal education. Newman has

* Assistant Professor, Department of English Language \& Literature, IIUC 
eloquently articulated what university education is and why liberal education should be at the centre of university education. Throughout, he maintains a holistic approach to university education. To him, it should not be fragmented, parochial or merely some sort of training. Newman observes:

...here are two methods of education; the end of one is to be philosophical, of the other to be mechanical: the one rises towards general ideas, the other is exhausted upon what is particular and external. (976)

Newman compellingly argues that knowledge ceases to be knowledge when it is particularized and indoctrinated. By going through the philosophic process of liberal education a student can develop his interdisciplinary ideas and is able to recognize "the relative disposition of things" (977). In the absence of the process, a learner could not be intellectually mature and, in the words of Newman, his/her state would be that of "slaves or children" (977) in spite of having some higher degrees.

Prof-Amanullah Ahmed shares the same views with Newman in his essay "On University Education":

University education must not be allowed to degenerate into mere mechanical transmission of professional or technological knowledge. Nor should it breed any narrowness of outlook in the students. Every subject, every branch of knowledge which is taught at the university should be treated as part of the totality of all knowledge....He (a university student) should have a wide range of interests and possess a power to see other people's points of view. He should be free from intellectual narrowness and should acquire a philosophical bent of mind so that he may be able to pass from the particular to the general (74).

It appears evident to us that the end-objective of liberal education, for Newman, is to produce a complete human being in the most comprehensive sense of the term. As Mark Pattison has said the real fruit of learning is "not a book but a man" (qtd in Ahmed: 75). And Newman very brilliantly epitomizes the personality of such a person:

But I must bring these extracts to an end. Today I have confined myself to saying that the training of the intellect, which is best for the individual himself, best enables him to discharge his duties to 
society. The philosopher, indeed, and the man of the world differ in their very notion, but the methods, by which they are respectively formed, are pretty much the same.... But a university training is the great ordinary means to a great but ordinary end; it aims at raising the intellectual tone of society, at cultivating the public mind, at purifying the national taste, at supplying true principles to popular enthusiasm and fixed aims to popular aspiration, at giving enlargement and sobriety to the ideas of the age, at facilitating the exercise of political power, and refining the intercourse of private life. It is the education, which gives a man a clear conscious view of his own opinions and judgments, a truth in developing them, an eloquence in expressing them, and a force in urging them.... He has a gift, which serves him in public, and supports him in retirement, without which good fortune is but vulgar, and with which failure and disappointment have a charm. The art which tends to make a man all this in the object which it pursues as useful as the part of wealth or the art of health, though it is less susceptible of method, and less tangible, less certain, less complete in its result (981-982).

Now, there is no denying the fact that society, along with all its constituting and shaping building blocks is always undergoing transformative changes. Education being one of the foundational blocks of society in many parts of the world (mostly in Asia and Africa) has been colonially shaped in the recent times. Colonizers, for obvious reasons, have tried to form and reform (deform is perhaps a better word) colonized societies according to their vested interest. Evidently, Macaulay's recommendation contained in his famous Minute on Indian Education is;

We must at present do our best to form a class who may be interpreters between us and the millions whom we govern - a class of persons Indian in blood and colour but English in tastes, in opinions, in morals and in intellect( qtd in Alam: 2)

So, the major objective of implementing colonial education system was to create a privileged class who would collaborate with the British regime. Perhaps the dangerous implication of the British colonial education system is the orientation of education towards jobs. The concept of "lekha pora kore je, gari ghora chore she" (those who study, ride carts and horses)" has been instilled into the psyche of the common people since the $19^{\text {th }}$ century, after the introduction of the colonial education policy in undivided India. The colonial education policy encourages us to mimic the western education system without assessing our own context. For this 
reason, we just import education/technology from the developed world but fail to assimilate these assessing our socioeconomic needs. For the same reason, we neglect many of our indigenous knowledge that could have been used for our development in different fields.

Thus, colonial philosophy of education essentially lacked liberal aims of education to develop a society culturally, intellectually politically and economically. On the contrary, it was introduced to create unthinking and uncritical job-seekers subservient to, not subversive of, the exploitative and unjust hegemonic imperial forces. Predictably, colonial objective of education has been successful to a large extent. Obviously, it has marginalized or ignored or eliminated holistic approach to education. This alien and imposed myopic vision of education has given birth to, in the words of Muin -ud- Din Ahmed Khan, "an uprooted firmament of supplanted personalities"(1). He also argues that the present day educational system of Bangladesh produces imitator graduates instead of creative thinkers (3). At the economic level, this led to maldevelopment (Parenti). At the philosophical level, it thwarted the rich indigenous growth of deep philosophic discourse. Perhaps, for that, we have not been able to reach standard levels in all other fields. Syed Sajjad Husain insightfully comments:

...there is a vital relationship between the standards of literature and philosophy. We have few examples of a great literature flourishing which does not have behind it the resource of a philosophical tradition (154).

In our context it appears to us that colonial impositions have strained the robust indigenous evolution of philosophic and literary growth. Colonial traditions have been uncritically favoured undermining the indigenous knowledge systems that used to have a long heritage of thousands of years. And until recently perhaps we have not been able to develop an essential rich critical culture which must "precede a true creative culture" (Arnold: 1397). The suffocative and indoctrinating tradition in education by the colonial forces, I think, is responsible in many respects for this. As Azfar Hussain (2007) puts it:

Almost all canonical figures in nineteenth-century English literature- figures that include even poets like Wordsworth, Coleridge, Tennyson, among many others, and figures who keep receiving thoroughly uncritical and unabashedly positive attention from many of our Englit folks in Bangladesh - were deeply and directly 
supportive of British imperialism. They even used God to justify imperialism itself.

Let us see, how, Coleridge invokes God: 'Colonization is not only a manifest expedient for, but an imperative duty on, Great Britain. God seems to hold out his finger to us over the sea'. Tennyson uses God even more strongly, as he says in a poem: 'God keep thee [empress-queen] strong as thou art free in the freedom of his law.'

But what is Empire's freedom? Its freedom is the freedom to deny freedom to the many, turning them into the 'wretched of the earth.'

Our best thinkers have discovered the colonial objectives of education severely straining liberal aims of education. Begum Rokeya Shakwat Hussain remarked, "It (colonial education) is unsuited to our needs and requirements and incapable of developing the distinctive thread of our national thought and culture" (503). Kazi Nazrul Islam always advocated a home-grown educational objective. To him, a true education must not ignore the identity of a people including its own language, culture, tradition, custom, heritage, etc. At the same time, a true education must be inclusive enough to include the best of things across the world (421). Nazrul says that it is degrading for the dignity of a people to lose its identity and individuality. Contrary to Nazrul's expectation to explore and strengthen "self", colonial objective has metamorphosed education into a mechanical process producing imitators rather than self- examining visionary people. In many of his essays and speeches, Rabindranath Tagore has offered a wealth of observations on the way contemporary educational institutions and teachers were imparting instruction in a manner that only served to make them functionaries of the colonial state and alienate students from their heritage as well as the world around them ( Alam:433).

Colonizers for their self- declared superiority inevitably inferiorize the colonized people. Education, in their hands, has been the best instrument to achieve their objective. While appreciating Nazrul's insightful power into colonial impact in India, Winston E. Langley refers to Hussein A Bulhan saying:

It was not simply the occupation of the land and the proletarianization of its people; it was more the occupation of their psyches- psyches laden with abuse, humiliation, and suffocating repression; psyches of 
people who were used and misused, and whose will was undermined at every juncture; and it was the psyches of self- loathing, because oppressor was associated with 'civilization and high values' and, therefore, superiority, while the oppressed was, by skin, color, habits, and all else that identified her or him, the personification of evil and inferiority .(50)

Thomas Szasz theorizes, "In the animal kingdom, the rule is, eat or be eaten; in human kingdom, define or be defined" ( qtd in Nandy: 112). Colonial education philosophy has denied the colonized people to define themselves; rather, they have been defined. Thus, it deliberately negated, in the words of Newman, the natural opportunity for them to form "a clear conscious view of his own opinions and judgements" (981). Obviously, we have enough reasons to feel that liberal outlook of education has been denied by colonially shaped education. Even in a post- colonial situation we still feel the colonial policy hangover in education. Many of the former British colonies have restructured their education policies to accommodate changed and changing needs of society. And, in this respect, education policy in Bangladesh suffers stagnancy. In the words of Gramsci, with our traditionally developed attitudes "we have unprecedented difficulties to overcome" (43) to brush off self-debasing, self-denying and indoctrinating colonial education policy. To do so, we might profitably use Newman's views on liberal education which necessarily advocates full-bloomed growth of the students through higher education.

Emphasising inclusion of moral education in liberal education Newman observes, "but education is a higher word; it implies an action upon our mental nature, and the formation of a character; it is something individual and permanent, and is commonly spoken of in connection with religion and virtue" (981). Our modern life, dominated by ultra-materialism and selfishness markedly suffers from the absence of a moral vision of life. Modern technology- based life has changed our life amazingly. But unassisted by spiritual and humanistic purposes of life it has, in a sense, diseased our life morally, more than it has been able to cure. Traditional and moral vision of life has been upside down. Perhaps, in the changed scenario, we could redefine the traditional saying as; "if character is lost, nothing is lost, but if money is lost, everything is lost". So, materialistic progress, unassisted by moral purpose of life has been a fertile ground for bestialities in human nature to flourish and is nipping its potential humane and moral possibilities. Perhaps, the root cause of the crisis and restlessness in today's world lies in "...the purposelessness from which modern man suffers" (Husain: 99). This purposelessness of life is generated by moral or immoral outlook of education. This essentially led educated people to be clever and 
selfish, not wise and altruistic. In this respect, modern education system, for the lack of spirituality and idealism, has been "a merely imitative westernization" (2).

Modern westernized secular education system lacks morality. Resultantly, it has given birth to a corrupting civilization of greed. And knowledge has become power with amoral foundation. This amoral objective has been treating human beings as mere animals without having spiritual purpose of life. It has made them obsessed with inhuman idea of "survival of the fittest", endangering and exploiting the lives of "Other". At the political level, this amoral education has given birth to predatory imperialism; at the economic level, it has given birth to sick and polluting type of development; at the social or familial level, this amoral knowledge system has been a fertile ground for the "absolute individualism into which western liberalism has degenerated" (Roper:1995) lacking a divine purpose of life and eventually it has degenerated into animalism negating the humanistic purpose of life. Realizing the corrupting influence of western civilization Rousseau preferred "noble savages" to "hopelessly civilized people". In my view, Rousseau succeeded in diagnosing but failed to prescribe comprehensively. Muin-ud-Din Ahmed Khan comprehensively argues that we must not sacrifice human conscience of the oriental civilizations at the altar of western civilization (6). Lack of morality or divine purpose of life has brought more pains than pleasures in our life despite the magnificent and blinding materialistic advancement. Syed Sajjad Husain conclusively remarks:

As long as man does not forget about this divine purpose which he can only partially comprehend at any stage in his evolution, he will not abandon that humility or renounce that meekness which alone can be a safeguard against the corruption and viciousness, cruelty and heartlessness, vanity and arrogance which characterize modern civilization and have landed us in a crisis. (98)

"Low, mechanical and mercantile" (979) objective of education is supported by John Lock (1632-1707) and his disciples (979). Their ultimate objective is utilitarian and market -oriented. To them, liberal education does not have any value in the market and so it is not useful. Newman has refuted the arguments strongly and convincingly proving that liberal education is good enough to be useful. In his view, "...though the useful is not always good, the good is always useful" (979). "Through scientific formation of mind", "building up ideas" and "the eye of the mind" the aim of liberal education, Newman asserts, is "to apprehend and contemplate truth" (978). More convincingly, Newman says that it is an 
acquired faculty of judgments, of clear-sightedness, of sagacity, of wisdom, of philosophical reach of mind and of intellectual self-possession and repose. For this to be achieved Newman's view is:

This process of training by which the intellect, instead of being formed or sacrificed to some particular or accidental purpose, some specific trade or profession, or study or science, is disciplined for its own sake, for the perception of its own proper object, and for its own highest culture, is called liberal education.(978)

And this "highest culture" could not be achieved by devoting oneself to any specific subject. If it so happens, Newman compares it with the "inordinate development" (980) of some specific parts, which neglects the "general health" (980) of the whole body. This "inordinate development" might be called maldevlopment. So liberal education, with its pluralistic aim discourages malpractice or maldevelopment in the academic context. Importantly enough, Newman does not show "disrespect towards particular studies, or arts, or vocations and those who are engaged in them" (980).

I do not mean to imply that the university does not teach law or medicine. What indeed can it teach at all, if it does not teach something particular? (980)

But Newman emphatically emphasizes that learners belonging to particular subjects should have "survey of all knowledge"(980) so that "he is kept of extravagance by the very rivalry of other studies"(980). Therefore, this encyclopedic view or holistic education can be cultivated not by studying any specific subject but by cultivating an enriched and continued culture of liberal education through all branches of knowledge. But commercial indoctrination of education has been straining the spirit of liberal education in our times more than ever before. Now, we are experiencing a world which, beyond debate, is ravaged and ransacked by the profit-maximizing capitalist monster. Hanry Shutt conclusively remarks that profit profit-maximizing capitalism has, by the last third of the twentieth century, outlived its usefulness as a vehicle for human progress (229). Roger Garaudy insightfully remarks:

The western countries are sick- with their blind economic growth and underdeveloped culture, wisdom and faith- which in turn breed violence and pointless lives, in capable of proposing and realizing human ends. The deceived countries are those made to believe that 
their future lies in imitating the sick countries.(qtd in Nandy:x)

This globalized capitalist monster is affecting and infecting every sphere of life in the name of market demands. For obvious reasons, education is not being spared. Because of overwhelming demand of the market, most students who make the top grade choose to study only the most marketable subjects which can get them jobs in multinational companies but will not be intellectually nourishing or enhance personal enhancement. This illiberal intellect fostered by fragmented education runs the risk of becoming a prey to extremist indoctrination. Besides, through the process, a learner is shaped and moulded according to the need of the market as if he was a machine devoid of infinite human qualities. In this respect Anu Muhammed rightly observes:

Education, training and research are organized in a way that reproduces tools, rather than independent academic person, of a broader machine of domination of few over many (9).

In this context, liberal education is being marginalized or shunted aside entirely by social attitudes and academic institutions that increasingly view that purpose of education as the provision of well-trained entry-level employees for the corporate sector. For many educators and concerned citizens the indoctrination of education and limiting its goals to profitmaximization for the enrichment of the few is a travesty which requires resolute rectification.

Marketisation of education has to do more with job skills than with character. It has culturally cloned human beings into mere consuming beasts and it essentially marginalizes or ignores the inborn human capacity for original thinking. Refuting this cultural cloning of human beings Farhad Mazhar (2006) opines that the prevailing notion of education presupposes that human beings, despite their differences from other beings, as thinking beings, are objects of manipulation, as if we are things to be moulded in educational factories.

Commodification or commercialization and corporatization have been straining the spirit of liberal education more than ever before. The tyrannical logic of the market now determines and dictates the production and consumption of knowledge. Thus knowledge has become a commodity that is bought and sold. In this context, Azfar Hussain (2006) observes that the idea of a university as a highest seat of learning is dying fast, while the university has already been a market place where students 
are treated like customers instead of learners, and where teachers act like sales persons.... Hence, the quality of education means "market value" not scholarship. Azfar Hussain (2006) further observes, "corporate values characteristically assume that money is more important than education; that owners or administrators know better than teachers and scholars."

Eventually, dictatorship of market ideology has indoctrinated and mystified the role of education only to ensure reign of profit-making ventures at the cost of human and environmental lives. In fact, dehumanized policies, discourses, and global hegemony of plundering and predatory capitalistic ideology have made a suffocating context for the liberal view to grow and thrive. Therefore, an "examined life" has almost become impossible which Socrates so reasonably longed for and which, I argue, might be the ultimate objective of liberal education. Far from being slaves to any indoctrination, Socrates desired human beings to have "teleological conception of things" ( qtd in Stumpf:40) through dialectic conversation. And only then, people could achieve true knowledge to do right acts that would harmonize with the human nature. Suffocating this humane aim of life, the unopposed tyranny of market ideology has made people the victims of wage-slavery. As a result, inhuman animalistic competitive scenario prevails in the sense that transnational corporations like Gulliver are feeding on the Lilliput-like toiling majority whose lives could be defined in the words of Hobbes, "... solitary, poor, nasty, brutish and short..."(qtd in Stumpf:217). To escape this apparently inescapable culture, Andrew Chrucky (2007) suggests: “...there is a prevalent myth that politics should be kept out of education. But the very opposite is what a liberal education should aim at. It should be an education in politicsbecause the aims should be to liberate us from wage-slavery and the whole culture of competition".

There is a growing tendency to indoctrinate the aim of education to serve the selfish personal motives at the cost of collective social welfare. The liberal aim of education is being strained and Noam Chomsky argues that it is pointless to discuss "the function of the university" in abstraction from concrete historical circumstances, as it would be a waste of effort to study any other social institution in this way (299). To support his view, Chomsky thinks it useful to recall a remark of Bertrand Russell:

Without rebellion, mankind would stagnate, and injustice would be irremediable. The man who refuses to obey authority has, therefore, in certain circumstances, a legitimate function, provided his disobedience has motives, which are social rather than personal. 
However, we could argue that university education must make students understand "circumstances" and motivate them to be dedicated more to social causes than his/her personal interests. Newman's advocacy for objectives of university education is almost the same, which can only be achieved through the cultivation of liberal education. Liberal education with its integrative approach and critical outlook has the objective to make people more humane at the personal level and more dedicated at the social level. But we have seen that colonial shaping; moral purposelessness and commercial indoctrination have severely strained the spirit of liberal education. Perhaps, that is why we have failed to achieve a desired human society at the local level as well as at the global level.

\section{Works Cited}

* All quotations of John Henry Cardinal Newman's "The Idea of A University" have been taken from The Norton Anthology of English Literature, Voll-II, Sixth Edition. Ed.Abrams, M. H.New York and London: W.W. Norton and Company Inc. pp. 976-982

Ahmed, Amanullah. Dickens and Other Essays. Dhaka: UPL, 2005.

Alam, Fakrul. Rabindranat Tagore and the Idea of a University: Shomaj O Sanskriti. ED. Bhuyian Iqbal. Dhaka: Moula Brothers, 2007.

------, Imperial Entanglements and Literature in English. Dhaka: Writers.ink, 2007.

Arnold, Matthew. The Function of Criticism at the Present Time. The Norton Anthology of English Literature, Voll-II, Sixth Edition. Ed. Abrams, M. H.New York and London: W.W. Norton and Company Inc.

Chrucky, Andrew. The Aim of Liberal Education. 26 november, 2007. http://www.ditext.com/chrucky/aim.html.

Chomsky, Noam. The Function of the University in a Time of Crisis: for Reasons of State. New York: Penguin Books, 2003.

Gramsci, Antonio. On Education, Selections from the Prison Notebooks. Ed. Hoare Quintin and Smith Geoftrey Nowell. Chennai: Orient Longman, 2007.

Husain, Syed Sajjad. Contemporary Writing in England and East Pakistan: Contemporary Bengali Writing. Second Edition Ed. Murshid Khan Sarwar. Dhaka: UPL, 1996. 
-------Civilization and Society. Dhaka. BIIT, 2002.

Hussain, Azfar. Whose education is it, anyway: class, cash and clash. Newage, third special Anniversary. 25 December, 2007.

http://www.newagebd.com/storelannio6leducation.html.

------. Of Disparities and Discrepancies: Micronarrative sequence; eighteen.20 April, 2007. http://www.newagebd.com/2007/apr/20/liti.html

Hussain, Rokey Shakwat. Education Ideal for the Modern Indian Girl. Rokeya Rachanaboli. Dhaka: Uttoron, 2008.

Islam, Nazrul. Shoittya Sikkha: Nazrul Rachanaboli. Vol-1, Dhaka; Bangla Academy, 2006.

Khan, Muin-ud-din Ahmed. Muslim Requirement in the Islamic and World Perspective. A Seminar paper presented at Regional Public Administration Training Centre, Chittagong. on 07 November, 2008

Langley, Winston. E. Kazi Nazrul Islam the Voice of Poetry and the Struggle for Human Wholeness. Dhaka. Nazrul Institute, 2007.

Muhammad, Anu. Development or destruction? (essays on global hegemony: corporate grabbing and Bangladesh). Dhaka: Shraban, 2007.

Mazhar Farhad. "Education as coercion and education as thinking." Newage. Third special Anniversary.25, December, 2007.

http://www.newagebd.com/store/annio6/education.html

Nandy, Ashis. Traditions tyranny and utopias (essays in the politics of awareness). New Delhi: Oxford University press, 2004.

------, The Intimate Enemy: Loss and Recovery of self Under Colonialism.New Delhi: Oxford University Press, 2006.

Shutt, Harry. The trouble with capitalism. An enquiry into the causes of global economic failure. Dhaka: UPL, 1999.

Parenti, Michael against empire. 20 January, 2009. http://www.michaelparenti.org/imperialism101.html

Roper, H.R. Trevor. In memoriam shills, (1910-1995). 16 April, 2009. http://www.necriterion.com/archive14loct95/shils.htm.

Stumpf, Samul Enoch. Socrates to Stare (A History of philosophy), Sixth edition. New York, McGrawHill, 2005. 